\title{
Development of the Productive Forces: An Ecological Analysis
}

\section{Jonathan Hughes}

Marxism has long been subject to criticism from the theorists of Political Ecology, and in recent years, as the concerns of Green thinkers have become harder to ignore, Marxists have begun to respond to this challenge, defending and sometimes amending Marxist theory in response to Green criticisms. This paper addresses one issue within this debate: the controversy over Marx's commitment to the growth, or development, of the productive forces. My aim is to dispute the contention of Marx's Green critics, that his concept of the development of the productive forces leads inevitably to the exacerbation of ecological problems, and, more speculatively, to suggest some advantages of using this concept to investigate ecological problems.

\section{Productive Forces, Ecology and Technology}

The productive forces consist of labour power and the means of production that labour power utilises in order to make its products. Since ecological problems are problems arising out of humans' dealings with nature, it is the natural components of the means of production that concern us. Ted Benton has argued that Marx neglects these natural components, but it seems to me that they can in fact be readily accommodated within Marx's account of the production process. ${ }^{1}$ The means of production consist of instruments and objects of labour, and Marx is clear that both of these originate from nature and have a persisting natural component. Objects of labour, or raw materials, are either given directly by nature or are natural objects modified by previous labour processes. ${ }^{2}$ Instruments of labour include: natural objects such as stones used as tools in primitive labour processes; tools and machines manufactured out of natural materials; and even the earth itself which serves as an instrument of labour in agriculture. And it is not only things which directly "conduct" the worker's activity onto its object which Marx recognises as instruments of labour; he also defines as instruments of labour in a wider sense "all the objective conditions necessary for carrying on the labour process", 3 a category which he intends to cover such things as workshops, canals and roads, but which will also without modification include the natural systems, physical, biological and climatic, upon which production depends. 
These natural components of the production process (shown schematically in Fig. 1) indicate two aspects of the process that make it liable to ecological problems:

(a) its dependence on naturally given raw materials, and

(b) its dependence on naturally given instruments of production.

But there is more. Of the materials used in the productive process only a part ends up in the product, and only some of these materials' properties are understood and exploited by the producers. The production process is therefore also liable to ecological problems in virtue of:

(c) its production of pollution and other environmentally detrimental unintended consequences. $^{4}$

If the development of the productive forces entailed an expansion of each of these ecologically problematic elements - demanding more from nature and having greater unintended impact upon it - then the claim that such a development must inevitably add to our ecological problems would appear to be confirmed, and Marx's Green critics vindicated. But the premise of this argument warrants further scrutiny. It has yet to be demonstrated that expansion of these ecologically problematic elements is a necessary consequence of the development of the productive forces, and in what follows I will give reasons for doubting that such a tight connection can be made.

Marx's Green critics often perceive historical materialism as a form of technological determinism. Leaving aside the question of determinism, I will argue that it is legitimate to identify development of the productive forces with the development of technology provided the latter is understood in a suitably broad sense. I will, however, argue against the claim that this technological development leads inevitably to a worsening of ecological problems.

Some commentators equate technology with tools and machinery, that is with instruments of production. ${ }^{5}$ Understood in this way, "development of technology" is a narrower concept than Marx's "development of the productive forces", since the productive forces include labour power as well as instruments. But the development of labour power consists primarily ${ }^{6}$ in the development of skills and knowledge, and this corresponds to what several commentators have noted is the original meaning of "technology": "knowledge about technique" or "knowledge of the industrial arts". 7 In fact, any actual development of technology must involve both the material and human elements, since the development and application of tools and machines are impossible without the knowledge to invent them and the skills to use them, ${ }^{8}$ and conversely the development of labour power is capable only of limited advance until it avails itself of new instruments of production. The development of 
technology may therefore be taken to include the development both of the instruments of production, and of labour power.

This account of technology still appears to leave one element of the productive forces, namely raw material or objects of labour, unaccounted for. ${ }^{9}$ I think, however, that insofar as Marx's phrase "development of the productive forces" can meaningfully be applied to raw materials, it must refer to such events as the discovery of new resources, of techniques to increase the viability of marginal deposits, and of new uses to which raw materials can be put, developments which are largely made possible by innovations in the instruments and techniques (i.e. the technology) of surveying, extraction and manufacture. Such developments can, therefore, be subsumed under the account of technological development given above.

What these considerations indicate is that developments of the productive forces are always developments of technology. It follows from this that whatever consequences are universally associated with technological development are associated also with the productive force development to which Marx is committed. Let us then consider what grounds there are for the belief that technological development must be ecologically damaging.

\section{Technological Development and Environmental Damage: An Inevitable Correlation?}

One fairly representative argument purporting to establish a necessary connection between technological development and ecological problems is advanced by Val Routley. She argues that the vision of an "automated paradise" offered to us by Marx "must be highly energyintensive and thus given any foreseeable, realistic energy scenario, environmentally damaging. ${ }^{10}$ However, whilst it is true that new technology may, and quite often does, waste more raw material, burn more fuel, and produce more pollution than the technology it replaces, Routley is wrong to assume that this must always be the case. ${ }^{11}$

Automation of production involves two elements: the replacement by machines of mental labour and of manual labour. The latter does indeed require the substitution of natural sources of energy for the energy previously supplied by human labour; thus the transition from handicraft production to machine industry implies an increase in the requirement for natural energy resources. But if the starting-point is today's highly mechanised production, which already is heavily reliant on such resources, the picture is different. In this context, automation must, to a large extent, mean the substitution of machines for the predominantly mental labour which humans expend in controlling or supervising machine production. In this capacity human labour contributes little to the overall energy requirements of the productive process, and it is quite possible that an automatic system will operate in a more energyefficient way than it would under direct human control, more than offsetting the relatively 
small amount of extra energy required to replace the supervisory labour. To take a familiar example, the energy required to perform a gear change on a car is small compared to that required for propulsion; so an automatic gearbox that selected the most energy-efficient gear more consistently than a human operator, could yield a reduction in fuel consumption greater than the small amount of extra fuel consumed by the mechanical action of changing gear. ${ }^{12}$

Routley's focus on energy use is typical of much ecological argument, but similar considerations apply to other resources. Just as the development of automation may lead to a net saving in energy consumption, so it may lead, by similarly improving efficiency, to savings in the use of other types of resource (i.e. raw materials), and to reduced emission of pollutants. This indicates that development of technology has a part to play in dealing with environmental problems; it does not, however, licence the assumption that technological changes alone will be sufficient to resolve ecological problems, since there are theoretical limits to what can be achieved in the way of increased efficiency, and even where improvements are theoretically possible there is no guarantee that the technological means to achieve them will be discovered in time to avert ecological problems, if indeed at all. ${ }^{13}$

The automation to which Routley (wrongly) objects consists of an increase in the productivity of labour, i.e. an increase in the ratio -

size of product

amount of direct labour required to produce it

- where this is achieved by means of technical innovation in such a way as to reduce the need for labour power. ${ }^{14}$ For others, however, the idea that the development of technology necessarily increases its impact on the environment rests on the assumption that the purpose of increasing productivity is to permit an increase in the quantity of goods produced, by loosening the constraint previously imposed by the requirement for labour power. ${ }^{15}$ Such a development would, other things being equal, lead to an increase in the quantity of resources consumed and an increase in the quantity of waste products. But as we have seen, other things are not always equal, because these consequences may to some degree be offset if the technology that increases labour productivity is also more environmentally efficient; it may therefore be possible to produce more with the same resources or even to produce more with less. Even so, given the limited scope and uncertainty of such efficiencies, development of technology aimed at an increase in production must be regarded as potentially problematic.

We have considered cases where technological development is aimed either at increasing the size of the product or at reducing the requirement for labour. However, it need not be aimed at increasing labour productivity at all. For even if the Greens' proposal for a halt to growth of production was enacted, and it was decided to forego further reductions in 
labour time, it would still be rational to introduce technological innovations designed to increase the efficiency with which resources are used and waste products disposed of, in order to reduce the ecological impact of existing levels of productive activity. Such innovations would appear to deserve the title of "technological development" no less than innovations aimed at maximising labour productivity.

Can this diverse range of objectives really be combined within a unitary concept of "technological development"? One writer who has attempted to do just that is I.C. Jarvie. He rejects the view that the appropriate measure of technological development in each case is determined by the branch of technology with which we are dealing, or the essential nature of its product. ${ }^{16}$ Such a view is unable to account for the fact that the objectives pursued may vary even within a given branch of technology, and that prime importance may be accorded to considerations usually regarded as "non-technical" and certainly extrinsic to the particular branch of technology, considerations such as economics, aesthetics, or (we may add) ecology. Instead, Jarvie argues that the appropriate criteria for measuring technological progress depend upon the concrete problem that is posed to the technologist, a problem that is always posed in a social context: "Whether the overriding concern is with accuracy, durability, efficiency, or what, is always dictated by the socially set problem and not the technological field." 17 The decision to assess progress in technology in this way has two consequences. First, on the assumption that willing the end entails willing the means, it raises the possibility of including the costs of production, broadly conceived to include ecological costs, in the assessment of technological progress. The second consequence, and the reason that the first one is only a possibility, is that assessments of technological progress will be relative to the social structure and the position of the agent within it; the range of factors that are included within the calculus of technological development will depend on the distribution of benefits and costs. A socially relative account of technological development, of this kind, may be less satisfying than a more readily quantifiable one, based on narrowly technological criteria, but it avoids arbitrariness in the choice of criteria and it permits critical evaluation, from the perspective of human needs, of established ideas of progress in different technological fields.

This last point is important since we want to know which criteria of technological development are included in Marx's concept of the development of the productive forces, and in this task our own linguistic intuition is an unreliable guide. Locating technological development in the context of interests and needs provides $u s$ with reasons for choosing between (or perhaps assigning different weights to) the various intuitively plausible criteria; and in order to ascertain which can be imputed to Marx we should consider what purposes are served by this development within his theory. 


\section{Development of the Productive forces: The Revolutionary Function}

Marx's best known discussion of the role of the productive forces is in the 1859 Preface, where he writes that the "relations of production...correspond to a definite stage of development of [the] material productive forces". ${ }^{18}$ The productive forces thus serve in some sense to explain the prevailing relations of production (which in turn explain the legal and political superstructure and forms of social consciousness). Marx's primary interest, however, is not in explaining individual social forms, but in the transition from one to another. This transition is explained by the development of the productive forces. The development of the productive forces explains changes in the relations of production because it creates the conditions in which such changes occur. We can therefore identify the key function of the development of the productive forces in Marx's theory as the creation of conditions for revolutionary transformations of society. I will call this the Revolutionary Function of productive development. The terms in which I have identified this function, however, are too vague to serve as anything more than a starting point. In order to determine which forms of technological development Marx can or must endorse, we need to look more closely at how the development of the productive forces performs its Revolutionary Function. Two elements of the Revolutionary Function can be discerned right away: the idea that the productive forces must reach a certain level of development to make possible a new social form, and the idea that at a certain level of development the productive forces undermine the viability of the old form. I call these the Enabling Function and the Undermining Function.

\section{The Undermining Function}

The idea that productive forces can come into conflict with, and thus undermine, the existing relations of production is central to Marx's understanding of the historical process. This conflict arises, he argues, when the productive forces develop to a point where they are constrained or fettered by the relations of production. The concept of fettering is invoked in several of Marx's and Engels's works, but receives its classic exposition in the Preface:

At a certain stage of their development, the material productive forces of society come in conflict with the existing relations of production, or - what is but a legal expression for the same thing - with the property relations within which they have been at work hitherto. From forms of development of the productive forces these relations turn into their fetters. Then begins an epoch of social revolution. ${ }^{19}$

Despite frequent use of the concept, however, Marx fails to provide a clear definition of what it is for the relations of production to fetter the productive forces. Several interpretations have been proposed: fettering may involve an absolute stagnation or decline of the productive 
forces, or a slower rate of development relative to the rate at which they would develop within an alternative set of relations; or it may be the use of existing forces rather than the development of new ones that is fettered, or some combination of development and use, such as what Cohen calls "net fettering": fettering of the used productive capacity that results from development of capacity and rate of use. ${ }^{20}$ These, and other variants, are set out in Fig. 2.

However it is interpreted, the Undermining Function does not commit Marx to any form of productive development under socialism, since he believes that capitalism is the last social form that comes to fetter the development of the productive forces. ${ }^{21}$ Neither does it commit him to any further idea of productive development under capitalism, if it is assumed, as Marx and Engels assumed in the Communist Manifesto, that the productive forces have already reached the stage at which they are fettered by capitalist relations of production. ${ }^{22}$ But, given the continued existence and productive growth of capitalism some century and a half later, could contemporary Marxists be committed to the view that fettering has yet to take place and that any productive developments must be supported, whatever their human and ecological consequences, as necessary steps towards the time when capitalism will become a fetter and be "burst asunder"? Such a view might perhaps be derived from Marx's comment in the Preface, that "No social order ever perishes before all the productive forces for which there is room in it have developed", a comment that was perhaps intended to account for the failure of the revolutions of 1848 to initiate the socialist transformation predicted in the Manifesto. ${ }^{23}$ I will argue, however, that although there may, among the various accounts of fettering, be some which will render this accusation true (absolute development fettering perhaps), no adequate account of fettering can have this consequence.

To do this I make use of two criteria for what is to count as a satisfactory interpretation of fettering. These are the "predictability constraint" and the "revolution constraint", derived by G.A. Cohen from Marx's account of fettering in the Preface. ${ }^{24}$ The predictability constraint dictates that a satisfactory conception of fettering must be one whose occurrence in the future can plausibly be anticipated. Cohen argues that absolute development fettering fails to meet this constraint since we have no reason to think "that, were capitalism, for example, to last forever, then the development of the productive forces would at some point entirely cease". ${ }^{25}$ Opinions may vary about the likely trajectory of productive development under capitalism, but if Cohen is correct then the grounds for supposing that fettering has yet to take place are weakened, since it is only if an absolute conception of fettering is assumed that the continued development of the productive forces is proof that they are not fettered. 
More pertinent to the present discussion is the revolution constraint. This states that "it must be plausible to suppose that when relations become fetters they are revolutionized." 26 Cohen argues that relative development fettering fails this test, because

the costs and dangers of revolution ... make it unreasonable to expect a society to undergo revolution just because relations which are better at developing the productive forces are possible, especially when those relations have not already been formed elsewhere and been seen to be better. ... Would workers overthrow a capitalism which has reduced the length of each computer generation to one year because socialism promises to make it nine months? ${ }^{27}$

The important point in this, for present purposes, is that fettering occurs when productive development is constrained in such a way as to give people (those who are members of the revolutionary class) reason to replace the fettering relations of production with others which remove that constraint. The question then is: under what sorts of circumstance do people have such a reason?

Our earlier discussion showed that technological development may be pursued for a plurality of reasons: increasing the quantity or improving the quality of product, reducing costs, reducing requirements for labour or natural resources, reducing pollution and so on. The next step is to recognise that any reason people have for pursuing technological development may also be a reason for removing constraints upon that development. It follows that in principle fettering may occur when any one of these objectives is hindered by the prevailing relations of production, although in practice each agent's interest in technological development is likely to involve several of these objectives, and constraints upon one form of development may be offset by development of another element of the bundle. There will, however, be limits to such trade-offs, particularly where peoples' most basic needs are concerned. Relations of production which allow productive technology to develop, but not in the ways that are required in order to mitigate its ecological impact, should therefore be counted as fetters as soon as the detrimental impact of this constricted form of development gives sufficient reason to abolish those relations. The Undermining Function therefore cannot require that such developments be tolerated as means to bringing about fettering, since a society that has room only for developments of this kind already acts as a fetter.

\section{The Enabling Function}

Absolute fettering - a halting (or slowing, or reversal) of productive development - cannot be sufficient reason for overthrowing existing relations of production unless there is some alternative that is both better and feasible. In other words, the Undermining Function of the development of the productive forces is only revolutionary if some such alternative exists. 
Which alternative relations are viable at any time depends, for Marx, upon the level of development of the productive forces. The effect that the development of the productive forces has in making new relations of production viable is what I call its Enabling Function.

Although Marx does not provide any general summary of the Enabling Function of productive development comparable with his account of its Undermining Function in the Preface, it too is integral to the theory of historical materialism. The idea that each set of relations of production becomes viable only when a certain minimum level of productive development is reached helps to explain Marx's conviction that society must pass through a succession of different relations of production before socialism can emerge. ${ }^{28}$ Each new set of relations is in its turn made possible by a development of the productive forces which progressively increases the quantity of goods produced beyond what is required to sustain the lives of the producers. As Cohen summarises it:

At the first stage, productive power is too meagre to enable a class of non-producers to live off the labour of producers. The material position is one of absence of surplus, and the corresponding social (or economic) form is a primitive classless society.

In the second stage of material development, a surplus appears, of a size sufficient to support an exploiting class, but not large enough to sustain a capitalist accumulation process. The corresponding social form is, accordingly, a pre-capitalist class society...

At stage 3 the surplus has become generous enough to make capitalism possible. ${ }^{29}$

Similar conditions apply for the disappearance of class society. Marx is clearly committed to the proposition that in a socialist society the increased productivity of labour made possible by the advance of technology should be used to reduce the burden of labour, ${ }^{30}$ yet he is equally clear that an increased level of output must be achieved. In The German Ideology Marx and Engels argue that, for communism to emerge successfully,

a great increase in productive power, a high degree of its development....this development of productive forces... is an absolutely necessary practical premise because without it want is merely made general, and with destitution the struggle for necessities and all the old filthy business would necessarily be reproduced. ${ }^{31}$

And similarly, in the Critique of the Gotha Programme Marx writes that the "higher phase of communist society" - characterised by its distribution according to needs - can be entered only "after the productive forces have...increased with the all-round development of the individual, and all the springs of co-operative wealth flow more abundantly." 32 Since technological development that is aimed at producing more goods has the potential to be ecologically damaging, it will be necessary to look more closely at these preconditions. However, there is nothing in the passages quoted above to imply that Marx is committed to an 
unceasing rise in output, and his commitment to reducing the burden of labour provides a reason for stabilising output once it is sufficient for the needs of a communist society. This would limit the ecological consequence of the development and allow the possibility of these consequences being offset by improvements in the ecological efficiency of productive technology. Indeed, if the reason communism requires productive development is to permit the meeting of human needs then improvements in the ecological efficiency of productive technology may be deemed an essential part of that development, since the ecological consequences that would otherwise ensue pose a threat to those needs.

\section{Explaining Productive Development}

I have argued that the Revolutionary Function of the development of the productive forces may in principle be satisfied by ecologically benign forms of technological development. It is not enough, however, to show such a development would satisfy the Revolutionary Function if it took place. In order to fulfil the explanatory role attributed to it by Marx it is also necessary that the proffered conception of productive development is one which we have reason to think will occur and will continue (provided capitalist fetters are removed at the appropriate stage) as far into the future as is necessary to create the conditions in which socialism can develop and mature. ${ }^{33}$ The question then arises of whether the mechanism which accounts for the tendency of the productive forces to develop will restrict the range of plausible interpretations of that development. As an example of such a mechanism I will examine Cohen's influential account of an "autonomous tendency for the productive forces to develop", which might appear to render that development insensitive to changes in circumstances such as the emergence of ecological problems. ${ }^{34}$

Cohen defines the autonomy of this tendency as "its independence of social structure, its rootedness in fundamental material facts of human nature and the human situation." 35 Whether historical materialist explanation requires such autonomy is a controversy which I will not enter into a here, except to say that the orthodox vision of an inevitable succession of relations of production, from the earliest human societies through to socialism, appears to depend upon the development of the productive forces being explained, at least in part, by something other than the relations of production within which it takes place. For Cohen, the tendency of the productive forces to develop arises from the conjunction of three facts: one about the human situation and two about human nature. First, humans live in a situation of material scarcity; secondly, they have the capacity to devise more powerful productive forces; and thirdly, they are rational enough to grasp the opportunities provided by this capacity to ameliorate the scarcity under which they labour. Given these facts, Cohen argues, "productive power will...tend, if not always continuously, then at least sporadically, to expand."36 
The trouble with this is that it seems unlikely that a developmental tendency based on unchanging facts about human nature and the human situation could undergo the required shift from the forms of technological development that have increased productive output to its present levels but at great ecological cost, to the forms which could play a part in reducing those costs. However, what Cohen does not say is that, important though these unchanging facts are, they only partially describe the material conditions under which humans exercise their inventive capacities and make decisions about their productive activities. For Cohen the chief problem faced by humans is having to spend a large proportion of their time producing their needs. Their ingenuity, according to Cohen, enables them to come up with solutions to this problem in the form of technological innovations to increase labour productivity, and their rationality ensures that the best solutions are adopted and retained. However, as was indicated by Jarvie, humans also face a range of problems arising out of the concrete social and material circumstances in which they find themselves. Acknowledging that these problems too may motivate the use of our innovative and rational capacities allows us to explain and predict the occurrence of new and varied forms of technological development including, for example, development aimed at reducing the quantity of scarce raw materials that must be consumed in order to meet our needs, or at reducing the deleterious unintended consequences of our need-meeting activity. And, given that the ways in which ecological problems affect people depend on their position within the social structure, this account also makes it plausible to suppose that the extent to which these ecologically oriented forms of technological development feature in the development of the productive forces will depend upon the structure of interests within the prevailing relations of production.

This last point suggests that, since we have now included among the motivations for productive development not only the unchanging facts of human existence but also the more specific forms in which humans may experience the effects of material scarcity, the tendency of the productive forces to develop is no longer autonomous of social structure. To investigate this let us consider Cohen's response to another argument against autonomy, put forward by Levine and Wright. They argue that since people's relation to the productive forces, and therefore their interest in productive development, depends on the social structure within which they live and the position they occupy within it, the tendency for the productive forces to develop cannot be autonomous of social structure but must be explained by a succession of "class-specific rationalities" corresponding to successive social structures. ${ }^{37}$ Cohen responds that indeed it is the class-specific rationality in operation at any given time which causes the productive forces to develop, but that the autonomy results from the application of universal human rationality at a higher level. Because of their rationality and because they live in circumstances of scarcity people select just those structures which promote and do not fetter the development of the productive forces, and it follows from this that the existence of a 
developmental tendency is independent of which structure and which class-specific rationality is in operation. ${ }^{38}$

So, on Cohen's account the selection of social structures underlies the tendency of the productive forces to develop and gives that tendency its autonomy. Cohen's assumption is that the motivation for the selection of structures is always the pursuit of improved labour productivity. I have argued, however, that the selection of structures may be motivated by various criteria of technological development, including ecological considerations, and that some elements of this motivation, concern about the ecological effects of production being one of them, are not universal but arise from concrete circumstances. ${ }^{39}$ Since, for Cohen, it is the selection of social structures that gives the productive forces their tendency to develop, it follows that this tendency may include whatever forms of development feature in the selection of structures. I will leave aside the question of whether the tendency of the productive forces to develop, as we have now described it, is an autonomous one. Suffice it to say that if it is autonomous then this is an autonomy which allows for the development of the productive forces to comprise different forms of technological development under different relations of production, and which therefore does not obviate the need for an ecological analysis of individual social structures.

The account presented here is conducive to an ecological Marxism in that it both allows the avoidance or amelioration of ecological problems to be included among the criteria for the development of the productive forces, and at the same time suggests that the channelling of productive development in an ecologically advantageous direction may not be realisable at will but may depend on the selection of appropriate social structures and that the range of technologically possible solutions actually available to a society may be restricted by the choice of structures open to it. However, this same variability of productive development under different social structures takes us back to a reservation registered earlier in the argument. In discussing the Enabling Function it was acknowledged that although there are reasons for interpreting modestly the expansion of productive output that Marx envisages as necessary for the development of socialism this is a matter which warrants further investigation. The reasons for a modest interpretation of that expansion have to do with the satisfaction of needs, which Marx sees as its purpose. If our needs include such things as increased leisure time and a healthy environment, then we have reason to limit the expansion of output and to redirect technological development towards these ends. There is, however, at least one persistent element in Marx's discussion of needs which challenges this argumenthis commitment to the growth of needs, which he appears to regard as both desirable and inevitable. This notion itself needs further investigation before definitive conclusions can be drawn, but what it suggests is, firstly, that if there is an ecological problem raised by Marx's concept of the development of the productive forces it lies not in its general explanatory role 
within historical materialism but in his conception of socialism, secondly, that more research is needed into the ecological implications of what Marx regards as the needs to be satisfied under socialism, and thirdly, that an ecological Marxism will have to specify the nature of its socialist objective more fully than Marx himself was willing to do. 
Fig. 1 Ecological Impact of the Labour Process

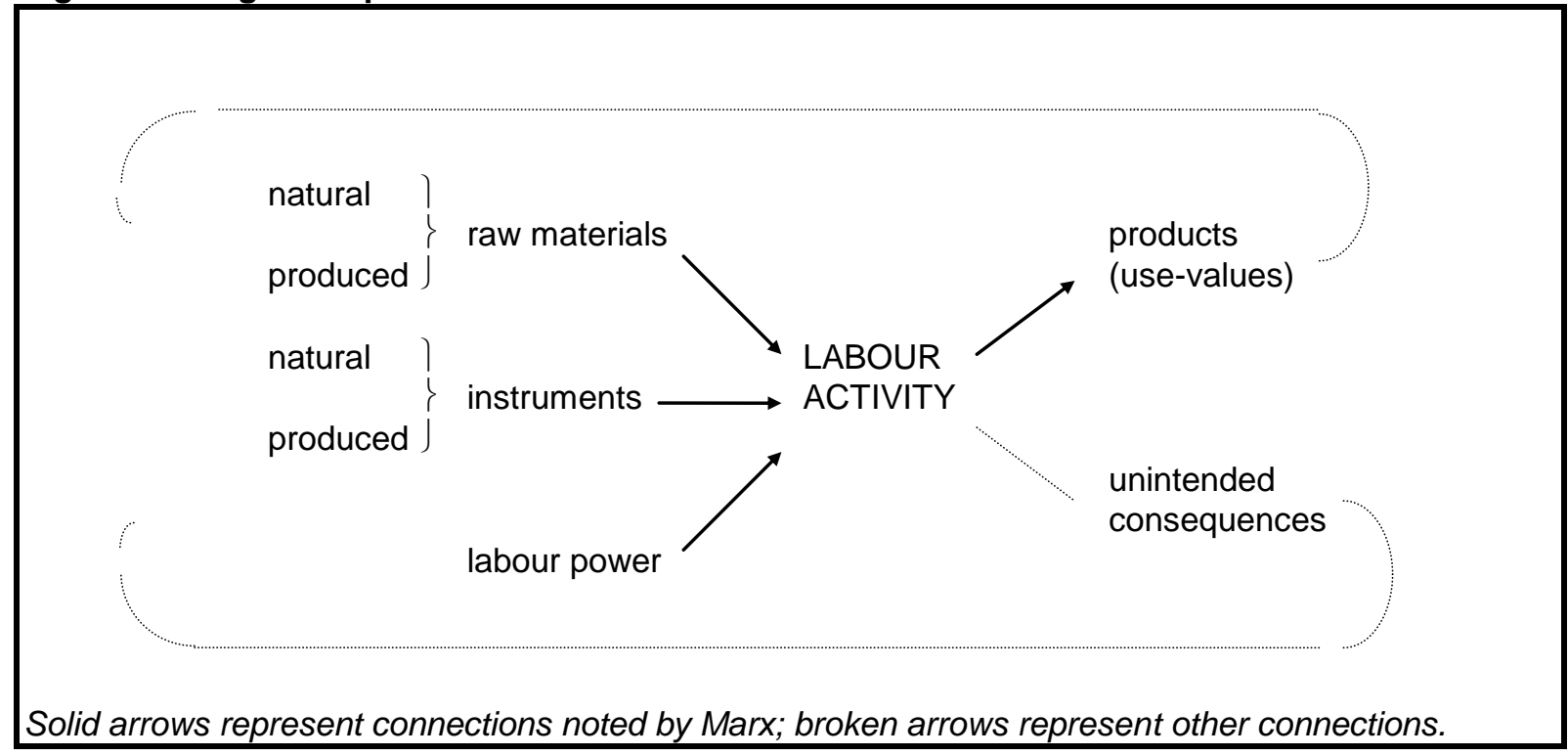


Fig. 2 Basic types of fettering

\begin{tabular}{|l|l|l|}
\hline & Absolute fettering & Relative fettering \\
\hline $\begin{array}{l}\text { Development } \\
\text { fettering }\end{array}$ & $\begin{array}{l}\text { 1. Absolute stagnation, i.e. zero } \\
\text { development of productive capacity } \\
\text { 2. Reduced rate of development } \\
\text { 3. Regression, i.e. negative } \\
\text { development }\end{array}$ & $\begin{array}{l}\text { Productive forces develop more } \\
\text { slowly than they would under some } \\
\text { alternative relations of production } \\
\text { (although not necessarily slower than } \\
\text { in the past) }\end{array}$ \\
\hline Use fettering & $\begin{array}{l}\text { None of the existing productive capacity } \\
\text { is used! }\end{array}$ & $\begin{array}{l}\text { A smaller proportion of the existing } \\
\text { productive capacity is used than } \\
\text { would be used under some alternative } \\
\text { relations of production }\end{array}$ \\
\hline Net fettering & $\begin{array}{l}\text { Used productive power (i.e. productive } \\
\text { capacity multiplied by proportion of } \\
\text { productive capacity used) is constant or } \\
\text { declining, e.g. } \\
\text { a. No increase in productive capacity } \\
\text { (= absolute development fettering 1) } \\
\text { b. Increase in productive capacity } \\
\text { remains unused }\end{array}$ & $\begin{array}{l}\text { Used productive power at future times } \\
\text { is less than under some alternative } \\
\text { relations of production }\end{array}$ \\
$\begin{array}{l}\text { c. Increase in productive capacity is (at } \\
\text { least) offset by a fall in the proportion } \\
\text { of capacity used }\end{array}$ & \\
\hline
\end{tabular}




\section{Notes}

T. Benton, "Marxism and Natural Limits", New Left Review, 178, 1989, pp. 51-86; cf. Capital, vol. 1, chapter 7.

Marx in fact reserves the term "raw materials" for the objects of production that have been processed in previous labour process, contrary to contemporary English usage.

Capital, vol. 1 (Harmondsworth, 1976), pp. 285-6.

I am using "unintended" in a broad sense to include consequences of an action which may be foreseen but are not part of the purpose of the activity. The effects of the production process upon the environment may be judged undesirable either because of their direct effects upon humans (e.g. in terms of health or aesthetic or recreational enjoyment of nature), or because they form a feedback loop, reacting upon the natural preconditions (objects or instruments) of the productive process and undermining its sustainability.

E.g. R. Grundmann, Marxism and Ecology (Oxford, 1991), p. 107.

"Primarily", since the development of labour power might also include development of the physical strength of workers.

C. Freeman, "Economics of Research and Development", in I. Spiegel-Rössing and D. de Solla Price (eds.), Science, Technology and Society (London and Beverley Hills, 1977), p. 225; E. Layton, "Conditions of Technological Development", in ibid., p. 199; cf. C. Mitcham, "Philosophy and the History of Technology", in G. Bugliarello and D.B. Donner (eds.), The History and Philosophy of Technology (Urbana, 1979).

G.A. Cohen argues, in Karl Marx's Theory of History (hereafter KMTH) (Oxford, 1978), p. 42, that knowledge, rather than physical instruments, is the more important part of technology, since instruments can be rebuilt given sufficient knowledge, but without the requisite knowledge the instruments become useless. This thought lies behind Marx's and Engels's comment, in The German Ideology (London, 1974), p. 72, on how the communications forged by international commerce assure the permanence of productive forces, which, while they remained local, were vulnerable to complete destruction. Marx also emphasises the priority of knowledge over material objects in Theories of Surplus Value, part III (London, 1972), pp. 226-227, and in Grundrisse (Harmondsworth, 1973), p. 295 where he describes machinery, etc. as "the power of knowledge objectified". 
Naturally given instruments of production are also excluded, insofar as they remain undeveloped, but as soon as they undergo development and become artefacts they may be included within the category of technology.

V. Routley, "On Karl Marx as an Environmental Hero", Environmental Ethics, 13, 1981, p. 242.

The harmful effects of many twentieth century technological developments are chronicled in

B. Commoner, The Closing Circle (London 1971).

My purpose here is not to suggest that automation of this kind can eliminate the ecological destruction associated with present levels of motor car use, but simply to illustrate the fact that the automation of technology envisaged by Marx need not be ecologically destructive in the way that Routley envisages but may contribute (albeit in a limited way, as I indicate in the following paragraph) to a reduction in its ecological impact.

This cautionary note constitutes the rational core of Green objections to "technological fixes" to ecological problems. Limits to the technological amelioration of ecological problems are determined for example by the quantity of materials and energy contained in the product and necessary for the transformation of the raw material into the product. These minima of inputs will also determine minima of waste products, constituted by that part of the fuel or raw material input that does not become incorporated in the product. Technology may, however, enable waste products to be converted into less harmful forms or to be used as resources in some other process.

Many Greens do of course recognise that technology has a contribution to make. A useful survey of Green attitudes is contained in C. Spretnak and F. Capra, Green Politics (London, 1985), p. 88. However the widespread use of the terms "hard" and "soft" to designate environmentally damaging and environmentally benign technologies does suggest a preference for traditional or "intermediate" technologies over modern "high" technology. There is certainly a place for the former but in many cases it will be the latter that is more environmentally efficient. See ibid.; also S. Irvine and A. Ponton, A Green Manifesto (London, 1988), p. 48.

This formulation comes from Cohen, $K M T H$, p. 56.

E.g. J. Porritt, Seeing Green (Oxford, 1984), p. 44.

This view can be found for example in H. Skolimowski, "The Structure of Thinking in Technology", in Mitcham and MacKey (eds.), Philosophy and Technology (New York and London, 1972).

I.C. Jarvie, “The Social Character of Technological Progress”, in Mitcham and MacKey, p. 52. 
This is not the only means Marx has at his disposal to explain the necessity of stage by stage social development, since he could also appeal to the idea that each set of relations can only emerge from a particular predecessor, in which some class has the motivation and ability to bring it about. However, it should be apparent from what follows that the successive "enabling" of relations of production by the development of the productive forces forms at least part of Marx's explanation of their sequential emergence.

$H L F$, pp. 109-110.

Ibid., p. 110. Cohen also doubts whether we have reason to think "that a persisting capitalism would, in time, display a deceleration in the rate of development of the productive forces".

Ibid., p. 110 .

Ibid., p. 111.

.

Preface to A Contribution to the Critique of Political Economy, in K. Marx and F. Engels, Selected Works (hereafter MESW) (London, 1968), p. 181; cf. The Poverty of Philosophy (London, no date), p. 92.

Preface, MESW, pp. 181-182. See also The German Ideology (London, 1974), p. 87; Manifesto of the Communist Party, MESW, p. 40; Grundrisse (Harmondsworth, 1973 Marx), p. 749.

These are the interpretations of fettering discussed in G.A. Cohen, History, Labour and Freedom (hereafter $H L F$ ) (Oxford, 1988), chapter 6.

This is a belief which needs some defence, given the stagnation and subsequent collapse of socialist economies in the late 1980s and early 90s, but one which Marxists cannot easily dispense with, since it is hard, even on grounds of distributive justice, to defend a productively inefficient system.

After describing how feudal relations became fetters upon the development of the productive forces and were "burst asunder", Marx and Engels write that "A similar movement is going on before our own eyes", and that "For many a decade past the history of industry and commerce is but the history of the revolt of modern productive forces against modern conditions of production, against the property relations that are the conditions for the existence of the bourgeoisie and of its rule." Manifesto of the Communist Party, MESW, p. 40.

Preface to A Contribution to the Critique of Political Economy, MESW, p. 182. 
HLF, pp. 155-156. Engels, The Origin of the Family, Private Property and the State, MESW, pp. 568-9, notes that the emergence of exploitative societies is dependent upon the growth of production: "The increase of production in all branches - cattle breeding, agriculture, domestic handicrafts - enabled human labour power to produce more than was necessary for its maintenance. At the same time, it increased the amount of work that daily fell to the lot of every member of the gens or household community or single family. The addition of more labour power became desirable. This was furnished by war; captives were made slaves. Under the given general historical conditions, the first great social division of labour, by increasing the productivity of labour, that is, wealth, and enlarging the field of production, necessarily carried slavery in its wake. Out of the first great social division of labour arose the first great division of society, into two classes: masters and slaves, exploiters and exploited." The accumulative character of capitalism is discussed by Marx in Capital, vol. 1, part 7.

See, for example, Capital, vol. 1, Chapter 10, especially Section 1 on "The Limits of the Working Day", and Chapter 15, especially section 3(b) on "The Prolongation of the Working Day"; also Grundrisse, pp. 701, 708.

The German Ideology, p. 56.

"Critique of the Gotha Programme", MESW, p. 320.

This requirement parallels the "predictability constraint" that Cohen places upon the interpretation of fettering.

Cohen's explanation of the development of the productive forces is not, of course, the only one on offer. I have chosen to investigate his account for two main reasons. Firstly, Cohen's account of the tendency of the productive forces to develop seems to me to be a plausible one, once the amendments suggested below have been incorporated. Secondly, the initial appearance that Cohen's account has, of being insensitive to the circumstances in which technological development takes place, means that it raises the problem that I want to consider in starker form than other, more "dialectical" interpretations which give greater emphasis to the role of production relations. What my argument below indicates, however, is: (i) that Cohen's account gives a more significant role to production relations than his critics sometimes realise (as shown by Cohen's reply to Levine and Wright); and (ii) that when the suggested amendments, motivated by Cohen's own argument, are incorporated, this yields an account of productive development which has the potential to be sensitive to a wider range of material circumstances than Cohen realises, including the emergence and development of ecological problems.

$H L F$, p. 84.11 
Ibid., p. 86.

A. Levine and E.O. Wright, "Rationality and Class Struggle”, New Left Review, 123, 1980.

Cohen, HLF, pp. 89-90, expresses this by saying that although there is an autonomous tendency for the productive forces to develop (since the existence of the tendency exists independently of which social structure obtains), there is not a tendency for the forces to develop autonomously (since productive forces only develop in the context of suitable relations of production). An alternative way of expressing this would be to say that there is a transcendental tendency for the productive forces to develop. This terminology expresses the idea that although social structure is involved causally in the development of the productive forces, the tendency is universal in virtue of the fact that it is a condition for the existence of any structure that it produces such a tendency.

It could be argued that ecological problems have the same source in the universal condition of material scarcity as the need to spend large amounts of time working, but so far as the selection of social structures is concerned the point is that whereas (if Cohen is to be believed) this scarcity always manifests itself in the latter way, it is only manifest in ecological problems when the productive forces become powerful enough and the population large enough to exhaust resources, cause serious pollution, etc.

\author{
Jonathan Hughes \\ Department of Philosophy \\ Keele University \\ Keele \\ Staffordshire \\ ST5 5BG
}

